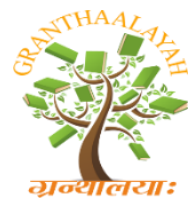

INTERNATIONAL JOURNAL OF RESEARCH - 目回 GRANTHAALAYAH A knowledge Repository

Social

\title{
METAPHORICAL EXPRESSIONS IN SHAFAK'S NOVEL “THE FORTY RULES OF LOVE": A COGNITIVE LINGUISTIC STUDY
}

\author{
Bushra Abd Hassan ${ }^{1}$, Hashim Aliwy Mohammed Alhusseini ${ }^{2}$ \\ ${ }^{1}$ MA Candidate at Department of English, College of Education for Humanities, University of \\ Wasit, Iraq \\ ${ }^{2}$ Ph.D, Assistance Professor at Department of English, College of Education for Humanities, \\ University of Wasit, Iraq
}

\begin{abstract}
This study attempts to analyse the metaphorical expressions used by the novelist Elif Shafak in her distinct novel The Forty Rules of Love. The core of any metaphorical expression lies in the intellectual conceptual, connotative and symbolic terms which require the readers to encipher such terms and grasp their intended meanings. Metaphors are the prominent linguistic devices which are deeply embedded in linguistic and literary expressions to enforce the suggestive meanings and symbolic meanings of such expressions. The researchers select four representative texts from the English novel The Forty Rules of Love in order to represent and cover all the aspects of Metaphor. To cover all the aspects of metaphor that are used in the novel, the researchers adopt a model which is based on Lakoff and Johnson's Theory of Metaphor (1980). Based on this adopted model to examine the aspects of metaphor, two levels of analysis are followed the contextual analysis and cognitive linguistic analysis. It is found that the Sufi thoughts and symbolisms are stated by using metaphor as a type of rhetorical devices.
\end{abstract}

Keywords: Metaphorical Expressions; Cognitive Linguistic Study; Lakoff and Jonson's Theory of Metaphor; Contextual Analysis; Cognitive Linguistic Analysis.

Cite This Article: Bushra Abd Hassan, and Hashim Aliwy Mohammed Alhusseini. (2020). "METAPHORICAL EXPRESSIONS IN SHAFAK'S NOVEL "THE FORTY RULES OF LOVE": A COGNITIVE LINGUISTIC STUDY." International Journal of Research - Granthaalayah, 8(2), 28-38. https://doi.org/10.29121/granthaalayah.v8.i2.2020.181.

\section{Introduction}

Metaphor is relevant to every aspect of life-especially in the human communication and discourse in that it is widely used in the narrative and political discourses. The most powerful formulas of metaphors are found in different rhetorical devices such as metonymies, similes, proverbs, and idiomatic expressions. Metaphors are both linguistic and literary tools which are imagined by linguistic expressions to facilitate the reference to symbolic meaning and certain connotations being positive or negative. Thus, such expressions support the style of Elif Shafak whose style is 
distinguished with different aspects of Sufism in such metaphorical expressions. Shafak in her novel "The Forty Rules of Love" sometimes uses a phrase which bears different meanings or can be interpreted in different ways; therefore, it is necessary to find a suitable model to analyse such expressions. As a result, Lakoff and Johnson's Cognitive Metaphor Theory (henceforth CMT) (1980) of analyzing metaphors is adopted. In analysing metaphors as a cognitive linguistic study, two levels of analysis are adopted to analyse the selected data. These are represented by their contextual analysis and the cognitive linguistic analysis. The cognitive linguistic analysis is mainly used to identify the types of metaphor and their functions because that may help to explore the intended meanings or at least the most appropriate explanations.

The present study aims at finding out the concept of metaphor and its basic forms, types, and functions that are used in Shafak's novel "The Forty Rules of Love”. This will be done by adopting the cognitive Linguistic analysis of metaphor to identify the Functions of metaphor, the most common types of metaphor that are used to reflect different aspects of Sufism to explicate the function of each type.

Some procedures are introduced to establish a general view of the phenomenon in question: Presenting a brief account of metaphor in relation to the cognitive linguistic aspects, adopting a model of analysis that is related to linguistics to be followed for data analysis. The adopted model focuses on( Lakoff and Johnson's Theory of Metaphor 1980), analysing some selected texts from the novel of "The Forty Rules of Love"' by highlighting special characteristics of the Sufi language such as the concept of metaphor, and finally discussing the results of the study to explore the findings of the study.

This study is limited to investigating the concept of metaphor in terms of certain linguistic theories, i.e., cognitive linguistic theory. Therefore, the current study is a qualitative in nature that aims to investigate the cognitive linguistic aspects of metaphor in Shafak's novel The Forty Rules of Love. Four texts from the English novel The Forty Rules of Love are chosen because these extracted texts represent specific aspects of metaphor.

\subsection{Statues and Nature of Metaphor}

Metaphor is a tool of conceptual economy, but that does not exhaust its role. It is also a tool of discovery, providing a way of imposing or discovering structure within novel or unfamiliar situations (Richards, 1936). Metaphors are a popular means of simplifying complex concepts. They enable us to make sense of abstract concepts by drawing parallels to concepts that are more easily accessible to us (Fetzer \& Gerda, 2007).

Metaphor is also an important means by which language develops. Metaphor may be an ornament to language but it is not merely an ornament. Language would certainly be much duller, and would more importantly have been unable to develop its complex and powerful resources of generalization and abstraction without the resources of metaphor (Searle \& John, 1979). However, metaphor consists of two issues, the target domain and the source domain. For example: 'Man is a wolf', in this sentence the word 'man' represents the target domain and the word 'wolf' represents the source domain. Through this metaphor, opinions shared by the members of our speech community about the nature of wolves determine our view of man (Fetzer \& Gerda, 2007). 
In addition, Lakoff and Johnson (1980) distinguish between two levels of metaphor: metaphorical concepts that exist in the cognitive level, and metaphorical statements, i.e., linguistics serves realizations on the surface level. Fromkin, Robert, \& Nina (2003) ensure that if metaphors are interpreted literally, they may appear anomalous. For example: 'Walls have ears', metaphor shows that this sentence is certainly anomalous but it can be interpreted as "you can be overhead even when you think nobody is listening". In some sense, the sentence is ambiguous but the literal meaning is so unlikely that listeners use their imagination for another interpretation. Fromkin et al (2003) emphasize that to interpret metaphors, one needs to understand both the literal meaning and facts about the world.

\subsection{Types of Metaphor}

According to Lakoff and Johnson (1980 a) metaphor is an aspect of rhetorical flourish and poetic imagination. They have been stated in their book "'Metaphors We Live By" that the language is the evidence to identify our conceptual organization. Therefore, metaphorical aspects are started with the effective function of a human beings' daily life.

Lakoff and Johnson (1990 b) identify the concept of metaphor from the idea of the 'Argument is War'. According to them, metaphorical aspects exist in every language of war arguments. Obviously, these arguments are not only stated by the terms of war, but also by actions of verbal and organized aspects of war. In addition, they illustrate that metaphor is a requirement of human awareness since metaphorical terms can facilitate the constructing and sympathetic of intellectual perceptions in aspect, physical or simple objects. Therefore, they identify metaphor into three major types: structural, orientational, and ontological or conventional metaphors.

\subsubsection{Structural Metaphor}

Lakoff and Johnson (1990 b) state that structural metaphor is identified by a number of metaphorical aspects that are metaphorically structured in terms of another. For instance, the aspect of 'Time is Money' can refer to the abstract idea of time in the literal idea of Money.

\subsubsection{Orientational Metaphor}

Lakoff and Johnson (1990 a) present that orientational metaphor is expressed by the terms of physical or spatial situation. In the case of 'Sad is Down and Happy is Up', sadness and Happiness are specified by the concept of spatial orientation, explicitly Down and Up. Consequently, the orientation of metaphor is not random but is based on our cultural and physical understanding such as 'I'm feeling up', 'I'm in high spirits', 'I'm feeling down', and 'his spirit sank'.

\subsubsection{Ontological Metaphor}

Lakoff and Johnson (1990 b) declare that the ontological metaphor provides an extraordinary basis for understanding ideas in aspects of physical objects. Consequently, there are different types of ontological metaphors with different purposes such as the idea of 'abstracts are things'. For example, she 'fell' in love, this may mean that she will be 'out' of the anxiety soon. In addition to 
these types, there are other classifications of metaphorical types as they will be shown in the analysis such as animating, synthesis, implicit, personifying, complex, and absolute metaphor.

\section{Cognitive Metaphor Theory (CMT)}

CMT is identified by Lakoff and Johnson in (1980) and then is originated to be identified as the 'conceptual metaphor theory'. This theory of metaphor presents the conceptual-semantic metaphors. Therefore, cognitive metaphor is identified as a charting of the cognitive structure or source area and a recipient or target area. Consequently, three major principles illustrate the aspect of the cognitive theory of metaphor: the human experience, the gestalt structure, and the systematic aspect of metaphor (Taverniers, 2002). Metaphor is identified as a poetic linguistic expression or novel, where series of words are used outside the conventional meaning of the same concept. Therefore, Goatly (2007) illustrates that metaphorical aspects are recognized as a general map which is characterized by using language as a tool to identify these generalization. Consequently, the fundamental way of understanding the concept of metaphor is to understand the method of how words have been joined in the metaphorical sentence.

In linguistics, the theoretical idea of metaphor is identified by the lingual meaning of context. Linguistically, theories of metaphor vary according to the theory of meaning whether it is explicit or implicit. Different theories have discussed from different linguistic, semantic, and pragmatic views. From lingual point of view, metaphor is discussed as a cognitive or conceptual aspect, this idea is identified by Lakoff and Johnson in (1980). They refer to metaphor as a cognitive aspect which is represented by a map between the source domain and the target domain. In addition, three major principles illustrate the aspect of the cognitive theory of metaphor: the human experience, the gestalt structure, and the systematic aspect of metaphor (Lakoff \& Johnson, 1980).

\section{Research Methodology}

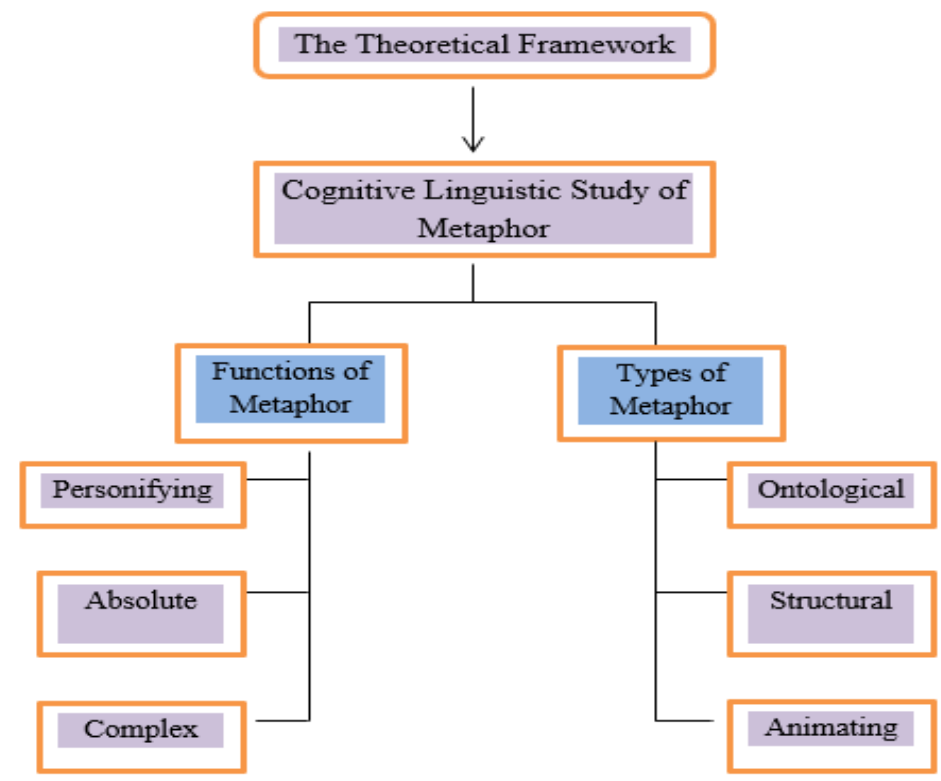

Figure 1: The proposed Theoretical Framework [adopted from Lakoffian theory of metaphor $(1980,1992)]$. 
The present study adopts a qualitative research technique. It specifies and discusses the metaphorical expressions that are used in the novel of Forty Rules of Love by the novelist Elif Shafak. The researchers have taken into their justification the statues and nature of metaphor, the types of metaphor, and cognitive theory of metaphor. The researchers emphasize on specific concepts of rhetorical devices that documenting as a cognitive linguistic study which is illustrated under the concept of metaphor as a cognitive linguistic study.

The adopted model of analysing the current study is represented by Lakoff and Johnson's theory of metaphor (1980), it is built on analysing the cognitive linguistic aspects of metaphor in Shafak's novel The Forty Rules of Love as it is presented in the theoretical framework above (See Figure labove) . Consequently, there are different justifications behind choosing this model for the cognitive linguistic analysis which is lakoff and Johnson's Theory of Metaphor (1980). the first one is illustrated by Lakoff and Johnson (1980) theory of metaphor (cognitive theory of metaphor CMT). Subsequently, CMT is identified by Lakoff and Johnson in (1980) and then has originated to discuss as the "conceptual metaphor theory". Accordingly, cognitive metaphor is identified as a charting of the cognitive structure or source area and a recipient or target area (See Figure 2) below:

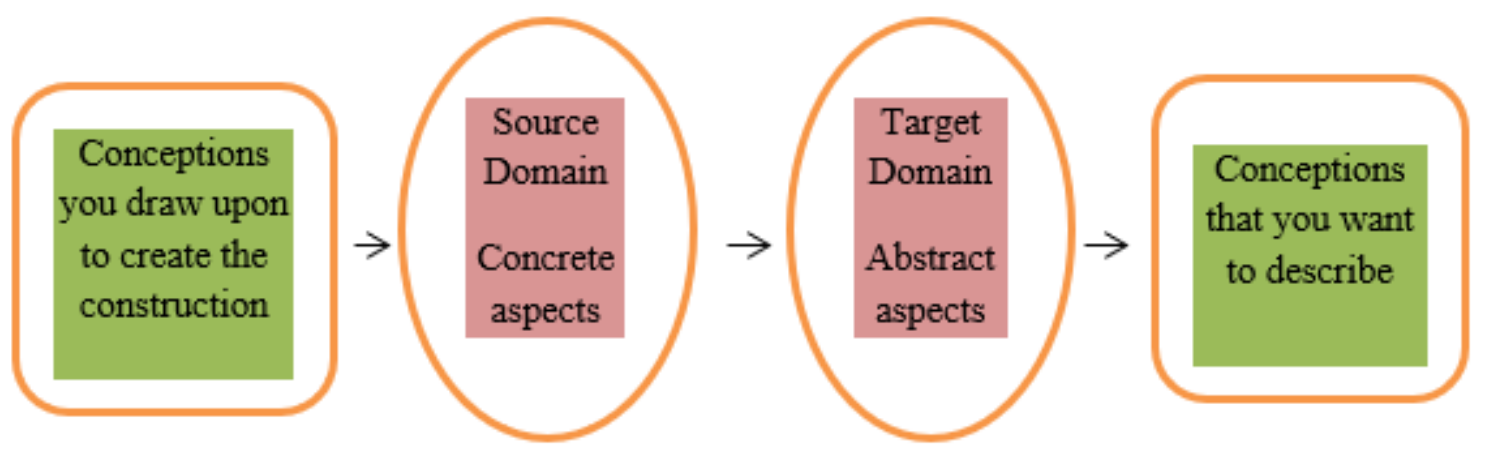

Figure 2: Cognitive Metaphor, (Lakoff, 1980)

\section{Criteria of Data Selection}

The data are selected from the English novel The Forty Rules of Love by the Turkish novelist Elif Shafak. The reason behind choosing this novel is that, the issues of metaphor are frequently present in the context of it. This novel is divided into different parts and each part reflects different ideas of Sufism. Moreover, this novel is divided into five parts as follow: -

1) The first part focuses on the concept of Earth (the things that are solid, absorbed, and still).

2) The second part identifies the idea of Water (the things that are fluid, changing and unpredictable).

3) The third part explains the concept of Wind (the things that shift, evolve, and challenge).

4) The fourth part clarifies the idea of Fire (the things that damage, devastate, and destroy).

5) The fifth part illustrates the concept of the Void (the things that are present through their absence).

Furthermore, Shafak has an Islamic experience beside the mode of Western belief. Such a fact enables her to discover and connect with the concept of Sufism in a mode which is easily understandable by the western people. Shafak's novel The Forty Rules of Love has brought the 
time of a present and past, and the culture of West and East. Rumi's story and his followers are presented through the awareness of different characters in this novel. The Forty Rules of Love focuses on the representation of the phenomenon of Sufism, as if there is an association between two different centuries (13th and 21th). Therefore, this structure reflects the Sufi ideas by a famous professor to a mystic poet through his expansion of a relationship between a traveling dervish and the darling affair of a wife with a mystic novelist (Anjum, 2014). As well as Firdous (2014) infers that Shafak's novel The Forty Rules of Love is generally described as an exciting novel by its construction. This novel describes the celebrated story of Rumi and Shams Al-Tabrizi in the $13^{\text {th }}$ century and this is contrasting with Ella's story (Jewish women in the middle age). Ella is a housekeeper that changes her miserable life by making a secret relationship with a mystic writer. Later, this novel is a broad study about the conflicting between heart and brain, infancy and perception. These aspects are stated through a spiritual journey to discover the real meaning of life. In addition to that, Anadolu-Okur (2013) presents that Shafak states the influence of Sufism and Rumi character through the Turkish literature, this idea is specified by Shafak in two different languages: For instance: The English language and Turkish one. Therefore, this idea is presented by using a single procedure to figure out different divergences between Muslims and non-Muslims. The phases of Rumi's existence and his spiritual journey are drawn in this novel by Shafak's plot of spiritual love.

\section{Texts Analysis}

\subsection{Extract (1)}

"This boy will open a gate in the heart of love and throw a flame into the hearts of all mystic lovers."

"an ocean is walking behind a lake.." (The Forty Rules of Love, P.68)

\subsubsection{Contextual Analysis of Extract (1)}

These lines are selected from the letter which is sent by master Seyyid Burhaneddin (one of the Sufis men in Kayseri) to the master of Rumi in Baghdad, February 1243 during the 13th century. The main theme of this letter is focused on explaining the early thoughts of person's transformation into a Sufi man.

\subsubsection{Cognitive Linguistic Analysis of Extract (1)}

Linguistically speaking, the writer uses a rhetorical device which is represented by metaphor. Since metaphorical aspects are based on source and target domains. The source domain is represented by the concrete or non-physical aspects, while the target domain is represented by the abstract or physical aspects. Metaphor is formed by a certain linguistic context. The expression or the word that generates metaphor is called linguistic vehicle which transfers the literal meaning (the source domain). Metaphor is stated by simple or complex words. Consequently, the writer uses different aspects of complex metaphor. The speech of the writer in this extract emphasizes this idea by her description of Rumi's character. 


\subsubsection{Type of Metaphor in Extract (1)}

Metaphor in this text is stated by the form of Ontological type, it is based on the idea of personification. Since it is based on the two aspects of source and target domains, as well as it is widely used in literature.

\subsubsection{Function of Metaphor in Extract (1)}

In this extract, the writer uses more than one level of metaphor. For instance: "open a gate", "throw a flame" and " an ocean is walking behind the sea" state the aspect of complex metaphor since this type blends uniform over another. It sheds light on the mixing between two things which are quietly different. In these expressions, there is no real gate and no flame throwing by Rumi, but these expressions symbolize the interpretation of Rumi's thoughts and the effect of his Sufi ideas on his students. In addition, Shafak in this text states another type of metaphor which is identified as animating metaphor. This type is stated by using words that are associated with nature to denote the characteristics of human beings. Consequently, this idea is illustrated by the description of Rumi as an "ocean walking behind the lake" which identifies his father.

\subsection{Analysis of Extract (2)}

"Every man is an open book, each and every one of us a walking Qur'an. The quest for God is ingrained in the hearts of all, be it a prostitute or a saint". (Forty Rules of Love, P.112)

\subsubsection{Contextual Analysis}

These two lines are uttered by Shams (Mohammed bin Malik al-Tabrizi, whose name is attributed to the city of Tabriz 'Iran nowadays', after that he is known as Shams, who is a real wondering dervish with unconventional ways and heretical proclamations. A mystic lover of the heavenly love, who sums up the concepts of mysticism in forty rules of love as is presented in the novel of Forty Rules of Love in Konya, October 17, 1244. In this extract, Shams emphasizes on the concept of divine love since it lies in the hearts of human beings from the moment they are born and they are waiting for the opportunity to appear. Therefore, human being is only an opened book waiting for the writing of our destiny.

\subsubsection{Cognitive Linguistic Analysis}

Some writers tend to penetrate different concepts of life, whether religious, social, political or historical. But what they do is to formulate events in their maturity that touches readers to reflect the issues of society or a certain period of time. The concept of Sufism is embodied by the writer in this novel through two characters of Rumi and Shams al-Din Tabrizi and their spiritual friendship. Shafak states the aspect of Sufism upon these two characters when Sufism is focused on the substance and content more than form, the heart and the inside more than the shape and appearance. Sufism is developed from and within abandoned modes of faithfulness (zuhd) during a period that protracts from the last decades of the $8^{\text {th }}$ century to the beginning of the $10^{\text {th }}$ century. 
In fact, the truth of the personality of Shams enters into the existence of divine love since childhood, where he is placed directly in the presence of God. Early Sufi Muslims are categorized by the refutation of sophisticated pleasures and influential fear of Allah. In addition, the Sufi people of the early stages are reflecting ascetics and poverty as the ultimate of their spiritual life. The Sufi people believe in fasting from the pleasures of the world, fighting the self from the ways of diligence in the worship, avoid distractions, and cleans the heart. Sufism emphasizes love as a way for living in this life as well as connecting with God.

Linguistically, the writer uses metaphorical image to state this idea by the comparison between two different aspects. Subsequently, there is no literal connection between the human being and the book as well as the aspect of Holly Qura'n.

\subsubsection{Type of Metaphor in Extract (2)}

Level of metaphor in this extract is illustrated by an absolute concept. Absolute metaphors are identified when there is no specious similarity between the source and the target domains. For instance, the comparison between the human being and the book as it is stated in this extract.

\subsubsection{Function of Metaphor in Extract (2)}

Function of metaphor in this extract is illustrated by ontological type since this type is stated by providing much less cognitive construction for target domain than structural one. It states by the comparison between the physical aspect and non-physical one.

\subsection{Analysis of Extract (3)}

"The sharia is only a boat that sails in the ocean of Truth. The true seeker of God will sooner or later abandon the vessel and plunge into the sea." "So that sharks might eat him up," Sheikh Yassin retorted, chuckling. "That's what happens to the one who refuses to be guided". (The Forty Rules of Love, P.259)

\subsubsection{Contextual Analysis}

These lines are selected from the conversation between Shams and Sheikh Yassin who is one of the religious scholars. In this extract, Sheik Yassin states the idea of Islamic religion by emphasizing that Islam is the only religion that should be followed by people. The events of this extract state in Konya, February 1246.

\subsubsection{Cognitive Linguistic Analysis}

Through this novel, the writer adopts a new character of a man who is accepted by God with a religious racism that transcends the role of the religious man. At the expense of the mystical sanctuaries, the Sufi is rejecting the idea of discrimination as the surviving band with its inner philosophy and divine love. Linguistically, the writer states this idea by illustrating the concept of Sharia as a boat. Literally, there is no connection between these two terms, so the writer metaphorically implicates the idea of religion as a boat. 


\subsubsection{Type of Metaphor in Extract (3)}

In this extract, metaphor is identified by complex level. For instance:" The sharia is only a boat that sails in the ocean of truth", this sentence is a metaphor because literally speaking there is no connection between sharia and the boat. Therefore, this level of metaphor blends a uniform over another. In addition, the concept of truth and ocean is built upon animating level because this level of metaphor connects between abstract and natural things. Generally, this metaphor uses the terms that are associated with nature and add them to the aspects that are used to indicate other things.

\subsubsection{Function of Metaphor in Extract (3)}

Function of metaphor in this extract is identified by Ontological type, since this type is illustrated by the philosophical aspects that have to do with the structure of the sentence. For instance: the aspect of Sharia as a boat, since Sharia is a physical thing that is connected with the boat which is non-physical thing.

\subsection{Analysis of Extract (4)}

"when you have both eyes closed to the world, a third eye opens in your heart. And only then do you come to realize that eyesight conflicts with inner knowledge. No eye sees so clear and sharp as the eye of love. After grief comes another season, another valley, another you'? (The Forty Rules of Love, P.341)

\subsubsection{Contextual Analysis}

These lines are uttered by Rumi in Konya, October 31, 1260. The writer in this extract states that the path to God must be seen with the eye of love and compassion which is passed from heart to head. The Sufi should see God through his heart since the way to God begins from the heart not mind and this is one of the Sufi aspects.

\subsubsection{Cognitive Linguistic Analysis}

One of the most important rules of Forty Rules of Love is that the path to God must be seen with the eye of love and compassion which is passed from heart to head, since it reflects on ourselves and our intimacy. The forty Rules of Love represents forty pulses in the life of the mystic, as if divine love is the way to God. Besides, divine love is rooted through a vertical relationship with God and another horizontal one with human being. Thus, the search for God and his love begins from the knowledge of the self, because it is the residence of God.

Linguistically, the writer uses metaphorical image to state this idea. Therefore, the sentence of 'a third eye opens in your heart' metaphorically implicates the idea of seeing and searching God through our souls and hearts because literally human being has only two eyes. 


\subsubsection{Type of Metaphor in Extract (4)}

The level of metaphor in this extract is illustrated by personifying type, for instance; 'a third eye opens in your heart', third eye is a physical concept linked to the human body which is the heart.

\subsubsection{Function of Metaphor in Extract (4)}

Function of metaphor in this extract is illustrated by structural type since this type of metaphor enables the speakers to comprehend the target domain by the construction of the structural one. For instance:" a third eye opens in your heart", the target domain of the physical aspect of " third eye" can be understand by the structure of the heart.

\section{Conclusions}

It is quite clear that to interpret metaphorical expressions literally, they would sound anomalous or non-sensual or at least the intended meaning cannot be enciphered. This, in return, effects on the understanding of the readers to such expressions. In studying the metaphorical expressions in Shafak's The Forty Rules of Love, the following conclusions are reached:

1) The present study identifies the cognitive linguistic aspects that are used in the selected data. It shows that the Sufi thoughts and symbolisms are stated by using metaphor as a type of rhetorical devices. Linguistically, the researchers identify the aspect of metaphor as a type of a cognitive linguistic study that is used to identify different aspects of the Sufi ideas. In addition, different functions and levels of metaphor are identified through the analysis such as the ontological and structural types in addition to the absolute, and complex levels of metaphor. Based on the analysis of the current study, metaphor is formed by a certain linguistic context. The expression or the word that generates metaphor is called linguistic vehicle which transfers the literal meaning (the source domain). Metaphor is stated by simple or complex words. Consequently, the writer uses different aspects of metaphor such as: 'open a gate', 'throw a flame', 'an ocean is walking behind a lake' 'life is a sequence of births and deaths', 'Moments are born and moments die'. Therefore, these aspects state the type of complex metaphor since this type blends uniform over another. It sheds light on the mixing between two things which are quietly different. In addition to that, the writer uses more than one level of metaphor such as synthesis, animating, and absolute type. Ex: 'I was a naked tree', 'Every man is an open book, each and every one of us a walking Qur'an'.

2) Throughout the analysis, the models of Lakoff and Johnson (1980) verify themselves in that Sufism in The Forty Rules of Love can be strengthened by certain linguistic aspects that are used by the writer to express the hidden meaning behind using the aspect of metaphor.

\section{References}

[1] Anadolu Okur, N. (2013). Historicising influence of Ottoman Mysticism and Mawlana Jalal AlDin Rumi through contemporary Turkish literature world. World Journal of Islamic History and Civilization, 3(3), 134-142. 
[2] Anjum, M.R. (2014). The Sufi Phenomenon, the case of Elif Shafak's The Forty Rules of Love. Global Journal of Human Social Science Research, 14(7), 22-45.

[3] Fetzer, A. \& Gerda, E. (2007). Political Discourse in Media: Cross Cultural Perspectives. Amsterdam: John Benjamines Publishing Company.

[4] Firdous, S. (2014). Language in India, Forty Rules of Love as a Bildungsroman. published dissertation. University of Mahila Vishwavidhyalaya, Khanpur Kalan. Retrieved from www. languageinindia.com ISSN 1930-2940 14:7 July, 2019.

[5] Fromkin, V., Robert, R., \& Nina, H. (2003). An Introduction to Language. Massachusetts: Thomson.

[6] Goatly, A. (2007). Washing the brain: metaphor and hidden ideology. Amsterdam: Philadelphia Benjamins.

[7] Lakoff, G \& Johnson, M. (1980). Metaphor We Live By. Chicago: University of Chicago Press.

[8] Lakoff, G. (1992). The Contemporary Theory of Metaphor. Ortony: University of Cambridge.

[9] Richards, I.A. 1936. The Philosophy of Rhetoric. Oxford: Clarendon Press.

[10] Searle, John. 1979. 'Metaphor'. In Metaphor and Thought. (ed.) Andrew Ortony (Cambridge: Cambridge University Press, 1979) pp. 92-123.

[11] Taverniers, M. (2002). Metaphor. In: Jef Verschueren, Jan-Ola Östman, Jan Blommaert and Chris Bulcaen (eds.) Handbook of Pragmatics. Amsterdam: Benjamins.

*Corresponding author.

E-mail address: bushraabdhassan93@gmail.com/alhili.usm@gmail.com 